\title{
Hotel Industry in Marrakech: Positions of Power are Still Little Feminized
}

\author{
Sara El Fallah \\ PhD student in Language Culture \& Tourism, Language Identity Media Heritage and Tourism Laboratory, \\ Faculty of Letters and Humanities, Cadi Ayyad University, 176 Zhong Guan Cun Street, Marrakech 40000, \\ Morocco \\ E-mail of the corresponding author: elfallahsarah@hotmail.com
}

\begin{abstract}
This article proposes a reading of the hotel sector by gender. Taking this concept into account is one of the main concerns for the development of the tourism sector in general and for economic development in particular, insofar as tourism occupies a preponderant place in Morocco's economy. At this level, a very abundant literature has focused on gender as a data linked to the evolution of the field and this at least since 1990. It's thus a question of studying the professional situation of women who are often victims of the glass ceiling, of professional segregation and find themselves confronted with various obstacles to occupy decision-making positions. The major interest of this research is to show that despite the constitutional reform and the efforts made by the State (particularly concerning the laws relating to gender and which have nevertheless enabled progress to be made with regard to the active participation women in the workplace). Notwithstanding, their presence remains insufficient as one goes up in the hierarchy (i.e., the highest-level positions). Marrakech in this case, out of a total of 240 classified hotels, there are less than 20 female hotel managers. (According to data from the Marrakech-Safi Regional Tourism Council: CRT). If during the last decade the situation of women has changed a lot, the fact remains that professional inequalities between men and women still persist today. A quantitative approach was naturally imposed on this study, which is based on in-depth questionnaire surveys, centered on the analysis of the professional situation of 202 women employed in the hotel industry in Marrakech, specifying several details which make it possible to understand the inventory and analyze the problem of inequality suffered by women in the tourism sector, particularly in the hotel industry.
\end{abstract}

Keywords: Women, tourism, hotels, gender, career, inequalities, power, discrimination, conciliation private life / professional life

DOI: $10.7176 / \mathrm{EJBM} / 14-4-02$

Publication date: February $28^{\text {th }} 2022$

\section{Introduction}

The gender is a sociological concept that "allows to distinguish the biological gender of the social gender, while emphasizing the character and culture and history, of the models of sexual behaviors" (Jane \& Méjias, 2014). It describes socially constructed institutional roles and is an integral part of mentalities and cultures. This division of the roles of activities and resources between men and women leads to an inequality between the two sexes which is manifested on different levels, especially at the professional level. The tourism sector doesn't escape this reality: having the same number of years of experience, the same diploma, women acquire much more difficultly than men the most elevated positions. The question of the status of women in the professional field in general and in the tourism sector in particular has been going on for years, a very debating topic. Despite all the reforms instituted by the Moroccan State which have been assigned the task of promoting the status and role of women, they have less chance of having the same career development and full of other disparities with his homologue men.

So, what is the place of the woman in the hotel domain in Marrakech to the highest positions?

Does the sub-representativeness of women in positions of power constitute a discrimination?

Are there any sexual functions? Does it mean that women are less professional? Less performing in comparison with men?

The present study constitutes an answer to all these questions with the aim of defending and valuing the place of women in hotel industry and with a view to encouraging women's careers in the face of obstacles and professional constraints. The study was carried out in the form of structured surveys with the help of questionnaires addressed to women working in the hotel sector in Marrakech, as well as with the help of two maintenance companies conducted first within the tourism delegation of Marrakech - Safi, the second level of CRT.

\section{Material and method}

These are surveys by questionnaires (they are 202 questionnaires in number) i.e., a sample which allowed us to choose women working in hotels of different categories located in the city of Marrakech in a random and 
independent manner. The questionnaire surveys were carried out in waves: a first that was took place during the months of January and February 2020 where we went to meet these women in their workplaces, a second wave, imposed by the confinement following the Covid19 pandemic and the shutdown experienced by the hotel activity in Marrakech, it was carried out through Google Forms during the months of June and July 2020 with the same target, namely hotel employees in the city of Marrakech. The questionnaire is presented as follows:

An introductory section including the category of hotel, the age group of the questioned as well as the approximate number of employees of the hotel in question.

A second section of multiple-choice questions dealing with the heart of the matter, namely the gender of the hotel manager, the differences between women and men (if there are already differences), in general these questions relate to the situation of these women in comparison with their male colleagues.

A section on the profile of the respondent: the position she currently holds, her professional experience, the diplomas she has obtained as well as her marital situation and more specifically the link with motherhood and work, in order to study the balance between private life and professional life.

And finally, A last section of questions containing open questions on the professional situation of women as well as some recommendations that they can propose to improve the situation of women in the hotel industry in general.

\section{Study zone}

The choice of Marrakech isn't arbitrary, it's one of the world destinations that make travelers dream, the city of Marrakech has a whole myriad of characteristics that make this area a tourist destination par excellence (S M Ben Massou), hence its name the tourist capital from Morocco. It has nearly 3 million tourists in 2019, all nationalities combined (according to CRT data). The ocher city is a creation of the Almoravids in 1070, historical capital of the South, Co-capital of the Kingdom with Fez for several centuries. It's located in the plain of Haouz in central Morocco at the foot of the Atlas Mountains. It's an imperial city « which cannot be reduced to a collection of monuments, including the square of Jamaa el Fna, or to a few activities that appeal to onlookers » (M sebti \& all., 2009). The city also enjoys a very pleasant climate almost all year round. In addition, it's endowed with an immense tangible and intangible heritage. All these elements make the region the first-class Moroccan destination. Thus, Marrakech has become, over the years, both the showcase and the spearhead of Moroccan Tourism (S M Ben Massou). Given all these reasons, the city is fertile ground for our quantitative study.

\section{Results and discussion}

In order to move from hypotheses to a quantitative study with qualitative conclusions, we thought of a fairly large sample: 202 anonymous questionnaires which aim to study and analyze the professional situation of women in the hotel sector, in particular the evolution of her career, it's also a questioning of received ideas concerning professional equality between men and women.

The results of our research seem alarming: Despite the progress made by women over the past ten years, male domination remains very strong, women face specific discrimination and inequalities: They are increasingly under- present as one evolves in the hierarchy and remain in the minority in decision

n-making and high-responsibility positions. Fewer than 20 female managers leave a margin of more than 220 male-run hotels across the city of Marrakech.

In other words, women occupy the positions of receptionists, quality managers, chambermaids, housekeepers, public relations managers, human resource managers, commercial managers, secretaries, etc. where men are directors, general managers and CEOs etc. It's true that there are women in Marrakech who have the function of hotel managers, however, they constitute a small minority and when this is the case, it's generally (with the exception of a few hotels such as Ibis Station of the international group Accor, Trois Palmiers, Les Jardins de L'Agdal, Kenzi Ménara Palace, Palm Ménara) of a family structure either that the director is the wife of the owner of the hotel or his daughter or his sister. We cite as examples Kech Boutique hotel, Al Andalous hotel, Mogador Opéra hotel, Le Galia hotel, Essaadi hotel, Farah hotel (formerly Siyaha, this hotel is a special case since the father of its director isn't the owner but he's a former hotel executive and currently he's the director of a large hotel in Agadir), Diwane hotel, etc. These statements have been confirmed through our interviews with Mr. Youbi Abderhman, previously responsible for classification and reception today within the Marrakech-Safi tourism delegation, as well as Dr. Tejan Mohamed, director of the Regional Association of the Hotel Industry within the CRT of Marrakech-Safi. In addition, figure (1) and table (1) also highlight this reality. 

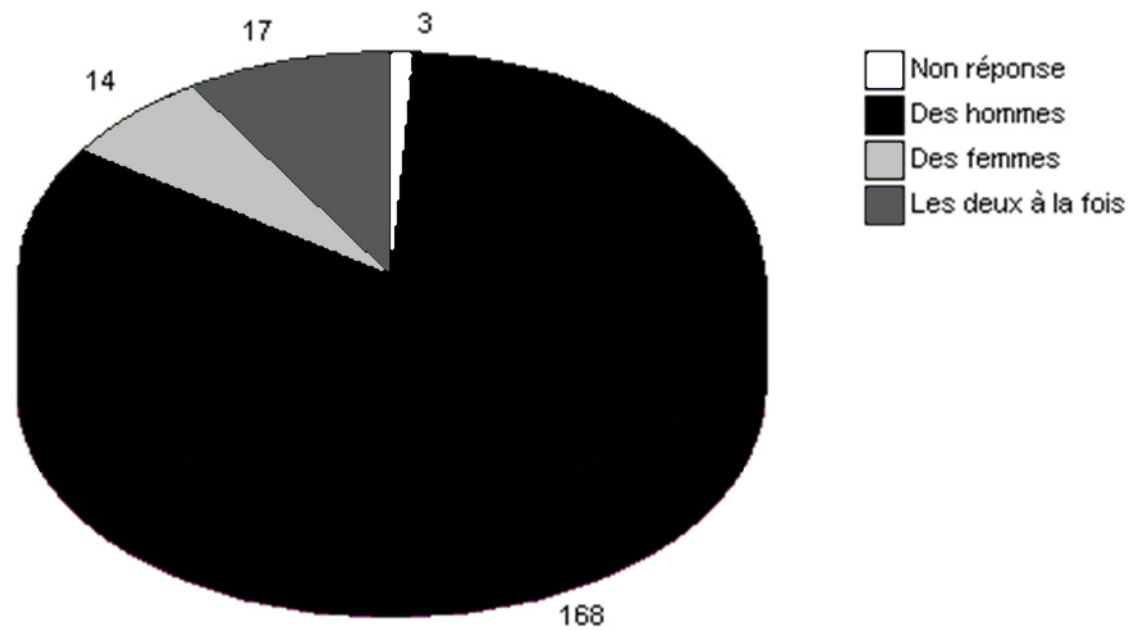

Figure 1: Study of the gender of the manager of the hotels in question

Table 1 Study of the gender of the manager of the hotels in question

\begin{tabular}{|l|r|r|}
\hline \multicolumn{1}{|c|}{ Genire } & Nb. oit. & Fréq. \\
\hline Non réponse & 3 & $1,5 \%$ \\
\hline Dles hommes & 168 & $83,2 \%$ \\
\hline Cles femmes & 14 & $6,9 \%$ \\
\hline Les deux à la fois & 17 & $8,4 \%$ \\
\hline ToTúL 0BS. & 202 & 1004 \\
\hline
\end{tabular}

Thus, according to our interviewees, the promotion of women is much slower in comparison to that of men, as shown in figure 2 and table 2, thus, women come up against obstacles and obstacles in the evolution of their career what is called the glass ceiling.

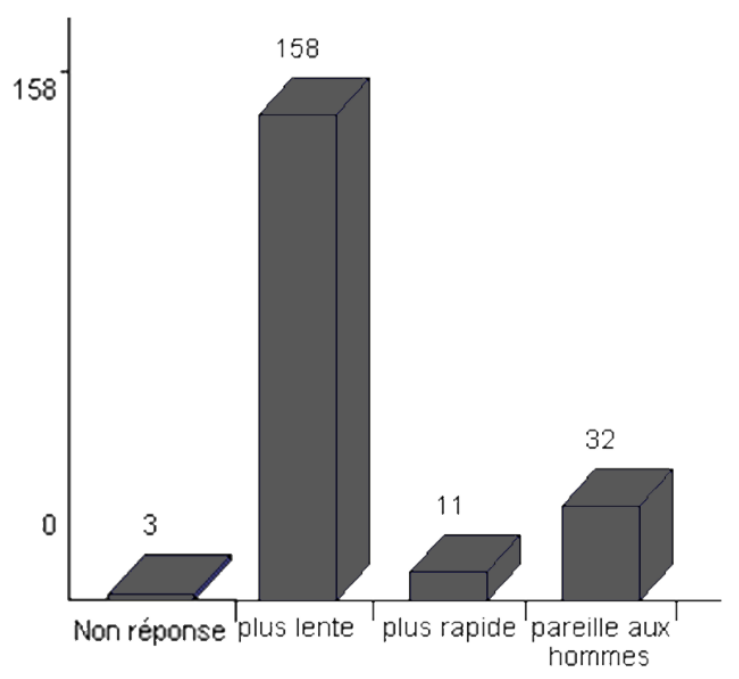

Figure 2: The promotion of women compared to that of men 
Table 2: The promotion of women compared to that of men

\begin{tabular}{|c|c|c|}
\hline Promotion desfernmes & WU. Cit. & Frêq \\
\hline Won réponse & 1 & $0.50 \%$ \\
\hline Flus lente & 158 & $78,20 \%$ \\
\hline Plus rapide & 11 & $5,40 \%$ \\
\hline Pareille al-x hommes & 32 & $15,80 \%$ \\
\hline TロTAL DES. & 202 & $100 \%$ \\
\hline
\end{tabular}

To justify and explain the phenomenon of the glass ceiling (Kanter, 1977 was the first to introduce this notion) that women experience, we asked open-ended questions that allowed these women to talk about their own particular experience and what they think of this discrimination in general. $93 \%$ of the answers show many explanations:

\section{- Morocco is a masculine society based on stereotypes, clichés and prejudices}

Stereotypes in general, whether positive or negative, guide the behavior of individuals. They dictate to each of the two sexes how to behave in social life. Moroccan society, for its part, assigns men and women quite distinct social roles: whether in terms of traditions, customs, the education of children from an early age, social norms, language or even cultural representations, all these elements combine in such a way as to confine each gender in its status, in a hierarchical position, moreover, "Since the ancient theory of temperaments, in fact, the masculine is on the side of hot and dry emotions ( anger, fury, boldness, hatred), the feminine, on the side of cold and wet emotions (modesty, gentleness, fear, modesty, compassion, languor). In the Western world, it's also considered that emotions are more feminine and that reason is more masculine » (BOQUET \& LETT, 2018).

Often, we tend to attribute to women weakness, sensitivity (even fragility), emotion, weak physique, fear, modesty, etc. men, on the other hand, are attributed strength, reason, bravery and self-control. This makes it possible to establish a hierarchy between men and women, therefore, men can exercise control and self-control over them, from there they are more apt to occupy decision-making positions and to be able to. Society brings out a model of normative report of the relationship of the couple which influences the professional relationship of the two sexes, this model gives to the man a privileged status compared to the woman. He's the head of the family and his wife is bound to obey him. However, and while the division of household chores has changed a great deal in recent years, the fact remains that work relating to the family sphere continues to represent a majority female constraint today. It's clear that the woman must balance her time in order to manage both her work and her domestic tasks.

A surprising observation is clear: a good number of women interviewed are themselves convinced by these stereotypes and think that these are rather masculine positions and that women who are sensitive and emotional by nature will never be able to assume responsibility for positions of responsibility decision.

- Marriage: A disruptive factor in women's careers

It seems that a single woman (according to the answers to our questionnaire) manages to reconcile professional and personal life much more easily than a married woman. It seems that when a woman seeks to succeed in her professional life and to be independent, she's doomed to loneliness. In this sense, despite the modernization of women and their professional development, marriage continues to force them to spend a lot of time doing domestic work, despite the various advances that Moroccan society has experienced, however, the traditional spirit still keeps its mark and continues today to impact the vision of Moroccan couples and to spare the man from these tasks which, normally, he's supposed to share with his wife. They are therefore forced to manage a double responsibility: that of work on the one hand and of marriage on the other.

- Motherhood is one of the main obstacles to the evolution of a female career

Almost $75 \%$ of the women surveyed said that the birth of their first baby had an impact on their work. As shown in (Figure 3) and (Table 3). All women working in this field, when they get pregnant, they go through practically the same changes either they go part-time or adapted to the new situation of mom after their maternity leave, or they change jobs altogether. Other women lose the position they had before childbirth and they don't manage to recover it after returning to work or even find themselves forced to accept transfers without even asking. On the other hand, being a father doesn't seem to have any repercussions on the employee's professional life. On the contrary, he can even benefit from salary increases following the birth of his children. (Since according to Moroccan law it's the father who is paid for the children).

These mothers felt left out of promotions, career development and post-maternity plans after returning from maternity leave. Almost all of the women, almost $90 \%$, say that it's difficult to find a way to look after their children with working hours, especially because the hotel industry can never have a fixed schedule such as the civil service where you start. At 9 a.m. and we finish at 4 p.m. Therefore, childcare poses a real obstacle for these employees. 


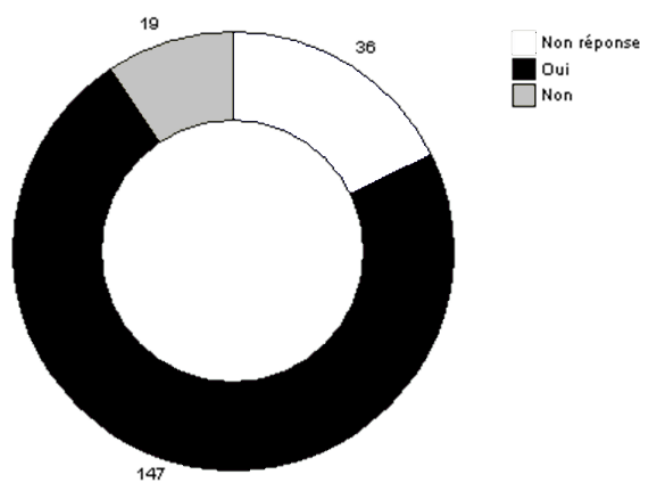

Figure 3: analysis of the impact of the arrival of the first baby on a woman's career

Table 3: analysis of the impact of the arrival of the first baby on a woman's career

\begin{tabular}{|l|r|r|}
\hline I'arrivée du premier bébé et son i mpact & Nb. cit. & F réq. \\
\hline Non réponse & 36 & $17.8 \%$ \\
\hline Dui & 147 & $72.8 \%$ \\
\hline Non & 19 & $9.4 \%$ \\
\hline TOTAL DBS. & 202 & $100 \%$ \\
\hline
\end{tabular}

- Few or no family-friendly practices within hotel establishments (family-friendly practices)

However, and in the majority of the hotels in question, almost $80 \%$ of the responses state that there is no familyfriendly initiative. (Figure 4) and (Table 4) this implies a difficulty in reconciling professional and private life.

family-friendly practices

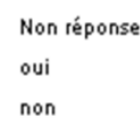

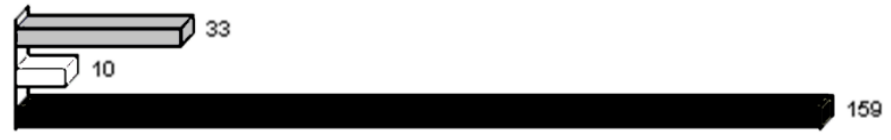

Figure 4: Few or no family-friendly practices

Table 4: Few or no family-friendly practices

\begin{tabular}{|c|c|c|}
\hline 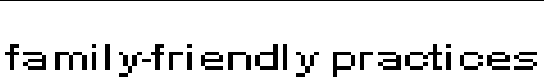 & Hb. oit. & F гёq. \\
\hline Horı réporıge & $3: 3$ & 10,38 \\
\hline i & 10 & $5, \square \%$ \\
\hline$\Pi \square \Pi$ & 159 & $79.7 \%$ \\
\hline 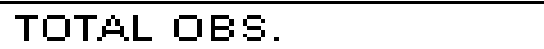 & $2 \square 2$ & 1010 \\
\hline
\end{tabular}

- Gender equality policies are sometimes utopian and not reality

The improvement in working conditions obtained through the intervention of trade unions, associations and the State, the law on professional equality between women and men has greatly improved the situation of women and has banished all discrimination from which the latter suffers. This concerns several levels: treatment, equal opportunities, or even neutrality with regard to stereotypes and prejudices. However, this is still not applied in Morocco or at least in Marrakech in the hotel sector, particularly those concerned by our questionnaire. These women overwhelmingly claim that they experience different treatment compared to men simply because they are women.

\section{- The impact of traditions and customs on society's view of the hospitality industry}

Another obstacle that prevents women from being promoted within their professions in the hotel sector, namely, the cultural dimension: the impact of Moroccan traditions and customs as well as illiteracy which continue to influence the visions and the ambitions of a woman who devotes herself entirely to her profession. In this regard, 
$91 \%$ of the women questioned affirm that Moroccan society, despite all the openness that the country currently enjoys, continues today to give a very bad place to women in the world of tourism believing in religion and preconceived ideas relating to the field given the extensions of the hours, the nocturnal and late evening meetings, the contact with foreigners, etc. (some women interviewed even used some Arabic words /fãndaka, zãndaka/). This unfortunately leads some women to prefer to pursue a career elsewhere and not in the hotel sector.

In short, if we observe all these elements in their entirety, we could say that the family situation is an essential factor in allowing the development of a female career, unfortunately, the work-family balance is a difficult problem to solve which concerns primarily women and not men. Our interviewees share in their answers all, without exception, a need for support to be able to reconcile personal and professional life, support from their superiors but also from their close husbands in this case. Women still bear the greatest share of family responsibilities, despite the fairly growing involvement of men. These women want to convince the managers of their hotels that they have talents to integrate into their work, that they want to evolve and move forward like their male colleagues, they only need one condition sine qua non namely, the confidence of their superiors. In addition, doubts about female competence, which have their origins in societal stereotypes, constitute a solid basis for arguments aimed at keeping women out of positions of power because of their incompatibility with the profession of management. Despite some progress, we quote in this case the Minister of Tourism, Handicrafts, Air Transport and Social Economy Nadia Fettah Alaoui who is a first for Morocco since she's the first woman to hold this position. however, considerable gaps remain between women and men in terms of employment, particularly in the most senior positions.

\section{Conclusion}

The professional situation of women working in the hotel sector in Marrakech is a bit paradoxical: Female participation is very active and continues to evolve very gradually, however, women remain under-present when it comes to positions of power. As a result, many inequalities continue to characterize the status of women. The law is very clear about equality between men and women, but its application on the ground remains almost utopian. Leading her professional career, her life as a woman, as a wife but also as a mother, remains a real challenge which, logically, should also be the same for men, notwithstanding, it's only for women. She finds herself faced with a real dilemma: her private life must not spill over into her professional sphere, in other words women must reconcile the two spheres to achieve a certain balance. Our study has clearly shown that it's very difficult to achieve this balance, especially with the arrival of children. Beyond motherhood, it's considered that being a woman is already a hindrance to the development of a female career. The future of hotel structures is strongly correlated to the family situation of the employee and the degree of balance between work and family. Feeling wronged, even discriminated against compared to their male counterparts, these women consider it essential to deal with professional equality in the hotel industry to change mentalities, but above all to balance career development.

\section{References}

Annie LABOURIE, "Gender and territory, what questions", Spaces populations societies, vol. 1, Lille, 7p, 2004.

Corinne Cauvin Verner "From cultural tourism to sex tourism: the logics of the desire for enchantment", Notebooks of African studies, "Tourism The quest for oneself through the practice of others", no 193-194, Paris: EHESS, 123-145p, 2009, https://doi.org/10.4000/africanstudies.18663.

Damien BOQUET \& Didier LETT the gender of emotions 2018 (Clio woman, gender, history).

Jane Méjias "Gender and society”, 2nd edition, Bréal, France, 128, 2014.

Marc Boyer "Tourism, a specific epistemology" followed by "The historian and tourism", Les Cahiers du GDR, no 2, 455-477 p, 2013, https://www.tandfonline.com/doi/abs/ 10.1080/07053436.1997.10715553.

Mathis Stock "Tourism, actors, places, issues, Paris: Belin. TEOROSDoss, 303,2008.

Mohamed Sebti, Youssef Courbage, patrickFesty, Anne-Claire Kurzac-Souali "People of Marrakech. Geodemography of the red city", Ined, 352p, 2009.

UN "Equality between men and women at the heart of decent work: International Labor Conference, 98th session”, Report VI, 2009.

Sabine Fortino "Diversity at work" La Dispute, 8p, 2002.

Si Mohamed Ben Massou, "What tourism for Morocco within the framework of a network society? The case of the Tensift-Al Haouz region", S.d., 325p, 2011.

Simon De Beauvoir "The second sex", t. 1, Paris. Gallimard, 416, 1949. 